
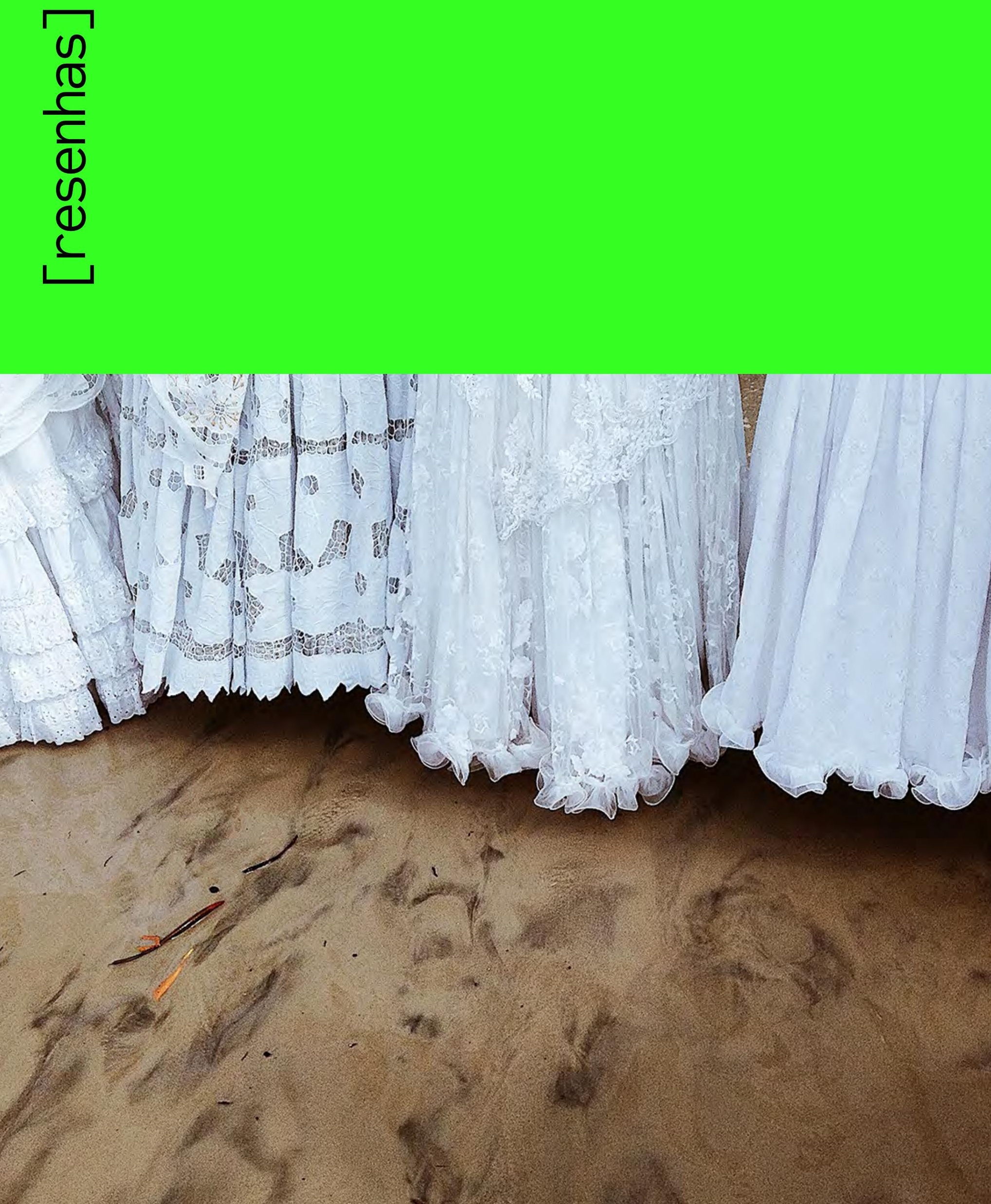


\section{O figurino do funk na perspectiva da cultura material}

Funk costume from the perspective of material culture

Resenha de: MIZRAHI, Mylene. Figurino funk:

roupa, corpo e dança em um baile carioca.

Rio de Janeiro: 7Letras: UFRJ, 2019.

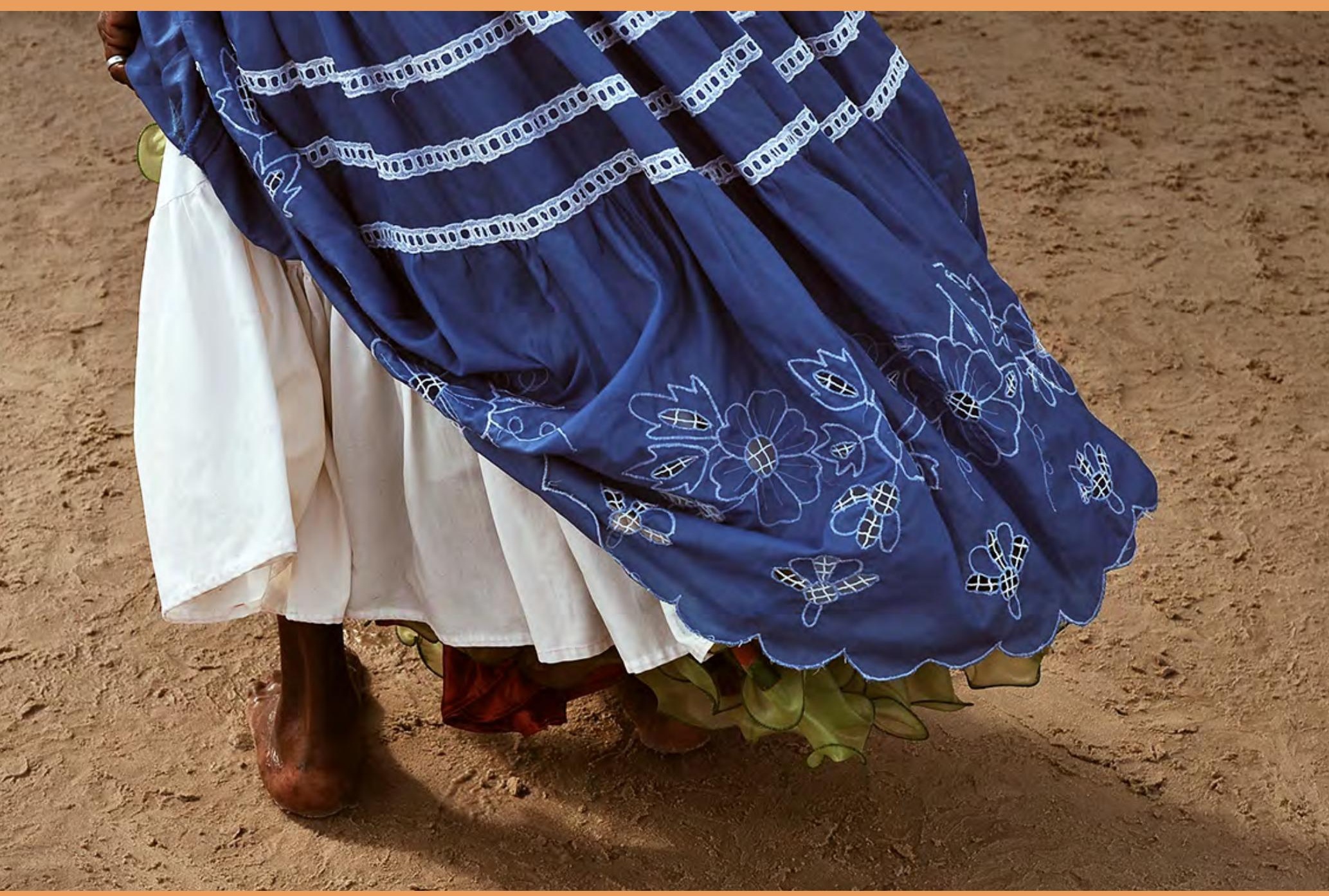


Maria Eduarda Araujo Guimarães ${ }^{1}$

ORCID: https://orcid.org/0000-0001-9968-2520

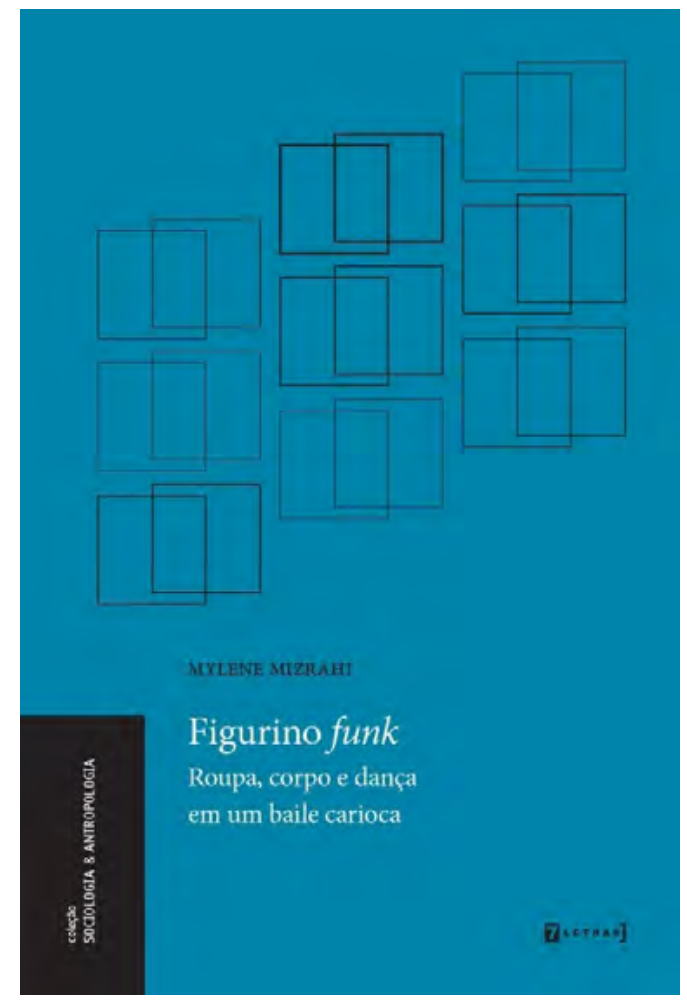

FONTE: Editora 7Letras. Disponível em: http://www.7letras.com.br/colecao-sociologia-antropologia/

figurino-funk-roupa-corpo-e-danca-em-um-baile-carioca.html. Acesso em: 30 out. 2020.

Gostaria de apresentar ao futuro leitor de Figurino funk: roupa, corpo e dança em um baile carioca três razões, embora existam outras, que justificam a leitura dessa obra, que não deve interessar apenas aos pesquisadores de moda, mas também aos que estudam cultura popular urbana, antropologia do consumo e metodologia etnográfica. Comentarei a seguir essas três razões: seu papel como documento histórico, a discussão sobre cultura material e o relato etnográfico.

\section{O livro como documento histórico}

Na apresentação da obra, a autora aponta que o trabalho é fruto da pesquisa realizada para sua dissertação de mestrado ao longo de 18 meses, entre 2005 e 2006, tendo essa distância de cerca de quase 15 anos entre a pesquisa e a sua publicação, tornando o livro um

\footnotetext{
${ }^{1}$ Doutora em Ciências Sociais pela Unicamp. Docente do Centro Universitário Senac de São Paulo. E-mail: guimaraes.madu@gmail.com. Lattes: http://lattes.cnpq.br/8875817815168670.
} 
documento histórico, pois retrata uma realidade que já não corresponde aos atuais bailes e ao cenário musical do funk.

De fato, nesses últimos 15 anos, o universo do funk se ampliou e se consolidou na cultura popular brasileira, não só em termos geográficos, com sua ascensão vertiginosa em São Paulo, mas pelo surgimento de diversos estilos dentro do seu estilo musical e pela sua grande presença na mídia tradicional e nas redes sociais, em canais de música e vídeo, especialmente o Youtube, no qual o KondZilla, autodenominado "o maior canal de funk do mundo" ${ }^{2}$, tem mais de 60 milhões de inscritos e visualizações que em apenas dois dias de postagem alcançam mais de dois milhões, caso do vídeo da música Metralha de raba, da MC Mirella, Tainá Costa e Mad Dogz que, divulgado em 30 de outubro de 2020, em 1 de novembro de 2020 já contava com 2.020.995 visualizações (KONDZILLA, 2020).

Da periferia para o centro, o funk hoje é presença não só na Zona Sul carioca. Em São Paulo, faz parte da trilha sonora das baladas da região da Vila Olímpia, frequentada por jovens de classe média e alta da cidade, e tem espaço em programas populares e de grande audiência na televisão aberta, como o programa do Faustão, da Rede Globo.

Para entender como o fenômeno do funk vem, ao longo dos últimos 30 anos, se transformando de gênero visto de forma muito negativa, associado à violência e com nenhuma visibilidade na moda que podemos chamar de dominante (CRANE, 2006), ou seja, aquela que aparece nos desfiles e nas revistas especializadas, para a condição atual, em que é a trilha sonora favorita de grande parte dos jovens brasileiros de diversas regiões do país, e tem em seus músicos referências para a moda, caso da cantora Anitta que, em agosto de 2020, passou férias na casa dos estilistas italianos Dolce \& Gabbana e posou para a marca, é preciso reconstruir o caminho que o funk trilhou na cultura brasileira. É nessa perspectiva que o livro de Mizrahi torna-se uma referência e, ao se juntar aos trabalhos de Hermano Vianna, O mundo funk carioca (1988), e de Micael Herschmann (organizador), Abalando os anos 90: funk e hip-hop: globalização, violência e estilo cultural (1997), auxilia-nos a desvendar o mistério do funk.

Com relação ao tema central do livro, a aparência dos jovens frequentadores dos bailes funk, a descrição que Vianna (1988) faz em seu relato sobre os bailes dos subúrbios do Rio de Janeiro assemelha-se à da autora, pois ambos localizam na aparência dos rapazes que vão aos baile uma certa imitação dos jovens surfistas, que, no contexto da cidade do Rio de Janeiro, significaria os jovens das classe mais altas.

O estilo masculino apropria-se de um estilo de vestuário que é mais conhecido como "surf wear", isto é, aquelas roupas que são desenhadas e vendidas para surfistas [...]. As marcas do "surf wear" que podem ser encontradas nos bailes são, é claro, mais populares e baratas do que as que se encontram em uma praia frequentada pelos surfistas da Zona Sul carioca. Mas estes últimos parecem ser o modelo de elegância da "rapaziada dos bailes" [...]. (VIANNA, 1988, p. 74)

2 Disponível em: <https://kondzilla.com/> Acesso em: 01 nov2020 
O estilo tipicamente "funkeiro" é de fato composto pela dupla t-shirt e bermudão, acompanhada de um par de tênis. É o estilo que eles designam como "normal" e que bebe na indumentária dos surfistas (MIZRAHI, 2019, p. 63)

Na análise das frequentadoras, a conclusão também é semelhante em termos da diversidade que podem apresentar.

O estilo feminino, à primeira vista, não parece ter uma característica marcante. Mas um olhar mais atento consegue perceber certos temas que sempre se repetem. As saias muito curtas e as calças compridas são justíssimas, realçando as formas do corpo das dançarinas. Existe também uma preferência por bustiês colantes e camisas curtas que deixem a barriga de fora. (VIANNA, 1988, p. 74)

Mas se os rapazes me permitiram uma classificação mais ou menos rápida de seus estilos, divisão similar não consegui estabelecer para a indumentária feminina. As moças possuem um guarda-roupa mais difícil de ser sintetizado. (MIZRAHI, 2019, p. 64)

Além da variedade de peças, que dificuldade uma classificação, como apontam ambos, a proximidade do corpo ainda é uma constante nos bailes, após quase 20 anos da descrição de Vianna.

O elemento constante nas roupas descritas acima [feminina] é a sua proximidade com o corpo, isto é, o fato da roupa ser justa e elástica. A elasticidade está a serviço de uma lógica cultural, a da roupa justa que revela o corpo [...]. (MIZRAHI, 2019, p. 92)

Esses exemplos permitem ver como as análises dos bailes e da música funk no período de 1988 a 2006 (data do estudo da autora) constroem um acervo de pesquisa para os elementos que se mantiveram e aqueles que se alteraram em termos de aparência nos bailes, e como esse estilo "funkeiro" deixou de ser apenas dos rapazes e moças das periferias e atualmente também é dos jovens das regiões mais ricas das cidades brasileiras. Sem os relatos dessas pesquisas enfrentaríamos muito mais dificuldades para entender o fenômeno em sua atual proporção.

\section{Os estudos de cultura material e a moda}

Ao longo do primeiro capítulo, a autora apresenta e discute aquilo que aponta como o cerne conceitual do trabalho: "as relações entre os sistemas classificatórios de bens e as abordagens da materialidade" (MIZRAHI, 2019, p. 20). Segundo ela, um dos objetivos da publicação do livro nesse momento, passados mais de dez anos da pesquisa, foi o de realizar um "raio-X do estágio em que se encontravam as discussões relativas às abordagens 
das coisas, nestas incluídas os bens de consumo, os objetos de arte, os adornos corporais" (MIZRAHI, 2019, p. 9).

Para Miller (2013), ao estudar a indumentária, é possível desconstruir uma certa visão acadêmica sobre como os objetos são capazes de expressar ou dar significado aos indivíduos, de forma a serem considerados como símbolos ou signos que representam as pessoas. Segundo o autor, em muitos aspectos, são os objetos que criam os indivíduos.

A materialidade da roupa, entretanto, não tem sido privilegiada nas investigações sobre a moda que consolidam esse campo de conhecimento a partir dos anos 1970, principalmente por ter sido a área de comunicação e semiótica uma das primeiras a dar atenção à moda, especialmente a partir do livro Sistema da moda, de Roland Barthes (1979). Nessa obra, Barthes define o método para a pesquisa em moda a partir da perspectiva: de que a análise do vestuário se dá em três níveis diferentes - o vestuário escrito, o vestuário imagem e o vestuário real, sendo as duas primeiras abordagens as que mais se concentraram na pesquisa da moda até o fim do século XX.

É nesse contexto de produção acadêmica que reside outro aspecto de grande relevância do trabalho da autora, pois "a argumentação teórica que se segue constitui um esforço de preencher as lacunas deixadas pelas abordagens nas quais os objetos são tratados como linguagem, como signo" (MIZRAHI, 2019, p. 20).

Dessa forma, a materialidade do objeto é o centro da discussão apresentada nesse capítulo e, ao lado de uma descrição detalhada da indumentária dos frequentadores que entrevista, autores como Marcel Mauss, Marshall Sahlins, Daniel Miller e Alfred Gell são discutidos a partir de um olhar sobre a produção e o consumo na sociedade contemporânea e o papel dos objetos, em especial os da moda, em sua capacidade de agência. Segundo Mylene, uma vez que o foco da pesquisa era a roupa, seria necessário

\section{[...] estudar a natureza física do objeto e sua relação com o corpo que o veste. Em outros termos, para entender os usos de um determinado bem pela pessoa, foi cru- cial compreender a relação estabelecida entre pessoa e coisa, como uma via de mão dupla, em que nenhum dos lados se sobrepôs ao outro. (MIZRAHI, 2019, p. 12)}

Embora ela enfatize que não se trata de um trabalho sobre moda (p. 31), o primeiro capítulo se detém também em uma revisão dos principais autores desse campo de estudo. Partindo de uma análise acerca das dificuldades que apresenta o conceito de distinção de Pierre Bourdieu, tão popular no Brasil nas investigações sobre o consumo cultural, em produções da cultura popular como o funk, pois estas seriam, na perspectiva do autor, percebidas como "uma estética da falta a que estariam condenados os membros das classes de baixa renda" (BOURDIEU, 2019, p. 34). Pensando com a autora, podemos entender que a escolha por trabalhos que se voltam para os efeitos da materialidade dos objetos, em sua capacidade de agência, de iniciativa, mostra-se, de fato, mais aderente aos propósitos da pesquisa.

Georg Simmel, Thorstein Veblen, Gilles Lipovetsky, Colin Campbell, Ted Polhemus e Mike Featherstone são outras referências que constituem o debate sobre as teorias da moda realizado pela pesquisadora nesse capítulo, buscando apresentar ao leitor ainda não 
familiarizado com essa bibliografia as alterações que partiram de uma abordagem centrada na distinção social para um entendimento de que as classes populares são também parte do universo da moda e, na perspectiva atual, cada vez mais influentes na indústria e no consumo de moda.

\section{0 relato etnográfico}

Talvez essa seja a parte que mais aprecio na obra de Mizrahi, pois leva o leitor para a festa, para os lugares e sons do campo de pesquisa. 0 relato etnográfico é em primeira pessoa, causando certo estranhamento aos leitores acostumados às normas da escrita acadêmica regidas pela impessoalidade, mas esta é a característica da etnografia.

Em etnografia, o autor é ao mesmo tempo seu próprio cronista e o historiador, enquanto suas fontes sem dúvida são facilmente acessíveis, mas também supremamente esquivas e complexas; elas não estão corporificadas em documentos materiais, fixos, mas no comportamento e na memória de homens vivos. (MALINOWSKI, 2016, p. 96)

A pesquisa etnográfica tem em Malinowski e na sua obra Os argonautas do Pacífico ocidental (1922) os princípios pelos quais as sociedades e as culturas distintas daquela de origem do pesquisador podem ser descritas e compreendidas, a partir do método desenvolvido por ele como o da observação participante. Para conseguir captar e reproduzir elementos dessa cultura do "outro" sem que recaia sobre a análise uma visão da sua própria cultura, Malinowski constrói regras para a investigação e aponta para a necessidade de utilização de um instrumento inseparável do antropólogo: o diário etnográfico. "Um diário etnográfico, mantido de maneira sistemática durante todo o curso do trabalho do etnógrafo num distrito, seria o instrumento ideal para esse tipo de estudo" (MALINOWSKI, 2016, p. 111).

Nos capítulos dois e três, Mizrahi apresenta-nos seu caderno de campo, incluindo os desenhos que fez para retratar os objetos da pesquisa, as roupas e os acessórios utilizados pelos frequentadores dos bailes, de modo que partilhamos o seu olhar sobre o objeto. Faz falta ao trabalho as fotografias que com tanto esforço a autora conseguiu captar, como ela nos relata no capítulo, pelos limites impostos pelos organizadores do evento, pois sem elas não temos os corpos que vestem o objeto, mas, mesmo assim, o objeto roupa é o foco do capítulo e por meio dele vamos entendendo, junto com a autora, sua agência, sua iniciativa em relação ao universo do baile. Também percebemos a solidão do pesquisador, que é, para Malinowski, uma necessidade para a apreensão da realidade observada. "Imagine-se deixado de repente sozinho, cercado por todo o seu equipamento, numa praia tropical, próxima a uma aldeia nativa, enquanto a lancha se afasta até sumir de vista" (MALINOWSKI, 2019, p. 96) 0 relato da pesquisadora nos dá essa dimensão solitária do trabalho etnográfico. 
Do chão posso ainda perceber a performance das moças e rapazes distribuídos pelos degraus das arquibancadas. Mas sozinha sinto-me desconfortável e tenho a sensação de estar sendo vigiada pelos seguranças. Na verdade, percebo, com o tempo, que todos estão sendo vigiados. (MIZRAHI, 2019, p. 74)

Poderia apontar no trabalho ainda muitas outras qualidades e discussões pertinentes ao campo dos estudos da cultura popular urbana, como a dimensão onívora e muitas vezes dissonante (LAHIRE, 2007) do consumo musical brasileiro, pois mesmo em bailes que trazem a identificação "bailes funk", a autora aponta-nos a presença de outros estilos musicais, como o suingue (p. 49) e o rap (p. 47), dividindo o mesmo espaço que, em muitos bailes, são as quadras de escolas de samba, e os mesmo personagens. Também poderíamos falar da presença, em várias descrições, das relações com outras produções da cultura popular e de massa no Brasil, como as telenovelas (BONADIO; GUIMARÃES, 2019), e sua influência na moda, como nas citações das saias "estilo darlene" (p. 65; p. 101), mas vamos deixar ao leitor as novas descobertas que o texto oferece. 


\section{Referências}

BARTHES, Roland. Sistema da moda. São Paulo: Editora Nacional: Editora da Universidade de São Paulo, 1979.

BONADIO, Maria Claudia; GUIMARÃES, Maria Eduarda. A moda brasileira e as telenovelas: consumo e visibilidade (1978-2001). In: BORGES, Camila; MONTELEONE, Joana; DEBOM, Paulo. A história na moda e a moda na história. São Paulo: Alameda, 2019.

CRANE, Diana. A moda e seu papel social: classe, gênero e identidade das roupas. São Paulo: Editora Senac São Paulo, 2006.

HERSCHMANN, Micael (org.). Abalando os anos 90: funk e hip-hop: globalização, violência e estilo cultural. Rio de Janeiro: Rocco, 1997.

KONDZILLA. Novidades. KONDZILLA. Disponível em: https://kondzilla.com/. Acesso em: 1 nov. 2020.

LAHIRE, Bernard. Indivíduo e mistura de gêneros: dissonâncias culturais e distinção de si. Dados, Rio de Janeiro, v. 50, n. 4, 2007, p. 795-825. Disponível em: http://www.scielo.br/ scielo.php?script=sci_arttext\&pid=S0011-52582007000400006\&lng=en\&nrm=iso. Acesso em: 28 out. 2020 .

MALINOWSKI, Bronislaw. Argonautas do Pacífico ocidental. In: CASTRO, Celso. Textos básicos de antropologia: cem anos de tradição: Boas, Malinowski, Lévi-Strauss e outros. Rio de Janeiro: Zahar, 2016.

MILLER, Daniel. Trecos, troços e coisas: estudos antropológicos sobre a cultura material. Rio de Janeiro: Zahar, 2013.

VIANNA, Hermano. 0 mundo funk carioca. Rio de Janeiro: Jorge Zahar Editor, 1988. 